\title{
Outcome Following Acute Spinal Cord Injury: A Review of 198 Patients
}

\author{
B. P. Gardner, MA, BM, BCh, MRCP, FRCS ${ }^{1}$, F. Theocleous, MBBS ${ }^{2}$, \\ K. R. Krishnan, MBBS, FRCS (Ed) ${ }^{3}$ \\ ${ }^{1}$ Consultant in Spinal Injuries, National Spinal Injuries Centre, Stoke Mandeville \\ Hospital, Aylesbury, U.K. ${ }^{2}$ Senior House Officer, ${ }^{3}$ Consultant in Charge, Mersey \\ Regional Spinal Injuries Centre, Promenade Hospital, Southport, UK.
}

\section{Summary}

The case histories of 198 consecutive traumatic spinal cord injured patients treated at the Mersey Regional Spinal Injuries Centre between 1975 and 1982 were reviewed. One hundred and seventy six were treated conservatively and 22 surgically. Functional outcome, complications, radiological reduction achieved and duration of initial hospital admission of the two groups are outlined. Prospective, multicentred trials are required to enable valid comparisons of treatments to be made. Patient expectations, state resources and local factors may determine which philosophy of spinal treatment is most appropriate for different centres in different countries.

Key words: Spinal cord injury; Outcome; Management; Complications.

The appropriate early management of the damaged spine of the acute spinal cord injured patient is hotly disputed (Bedbrook, 1981; Donovan, 1984; Frankel, 1969; Gaines, 1984). Functional outcome, economic factors, patient expectations and the incidence of complications are important features helping to determine the philosophy adopted by different centres.

The damaged spine is managed in the Mersey Regional Spinal Injuries Centre following principles developed by Ludwig Guttmann (Guttmann, 1973). This study investigates some of the results of the application of this approach.

\section{Patients and methods}

The case histories of 198 consecutive acute traumatic spinal cord damaged patients treated at this centre between 1975 and 1982 were reviewed. To reduce inevitable bias, the second author collected the majority of the data since she had not been involved in the management of any of the patients during their 
first admission. Data was analysed using a DBASE 11 database file in a Sirius computer.

\section{Results}

The age of the patients in this series is indicated in Table I. Because it is not always possible to admit elderly spinal cord injured patients, the relative

Table I Age at injury

\begin{tabular}{cc}
\hline Decade & Number \\
\hline $0-9$ & 1 \\
$10-19$ & 38 \\
$20-29$ & 55 \\
$30-39$ & 34 \\
$40-49$ & 32 \\
$50-59$ & 15 \\
$60-69$ & 18 \\
$70+$ & 5 \\
\hline
\end{tabular}

incidence may be commoner in this age group than is suggested by these figures.

Of the 198 consecutive patients treated between 1975 and 1982, only 22 had spinal surgery in the acute stage. One other patient had an anterior decompression several months later and is not included in the operated group. The operations performed are indicated in Table II. Many of these were performed outside Great Britain. None were carried out in this centre although the majority of patients of this series were admitted within 48 hours of injury.

Table II Type of surgery used

\begin{tabular}{lc}
\hline Surgery & Number \\
\hline Laminectomy alone & 7 \\
Posterior (spinous process) plates & 6 \\
Harrington rods & 2 \\
Other posterior reduction $+/-$ fusion & 5 \\
Anterior fusion & 1 \\
No record & 1 \\
\hline
\end{tabular}

Plain radiographs provide the basis for the radiological evaluation of the spine in this centre. Outcome is indicated in Table III. It was considered good if perfect repositioning was achieved, moderate if some disturbance of alignment remained and poor if little reduction was achieved.

Table III Radiological outcome

\begin{tabular}{lccccc}
\hline & Total cases & Good & Moderate & Poor & Unknown \\
\hline Surgical & 22 & 11 & 6 & 2 & 3 \\
Conservative & 176 & 101 & 57 & 14 & 4 \\
\hline
\end{tabular}


Table IV Spinal column/neural tissue complications

\begin{tabular}{lcccccccc}
\hline & $\begin{array}{c}\text { Total } \\
\text { cases }\end{array}$ & $\begin{array}{c}\text { Total } \\
\text { compli- } \\
\text { cations }\end{array}$ & $\begin{array}{c}\text { Sympto- } \\
\text { matic } \\
\text { deformity }\end{array}$ & $\begin{array}{c}\text { Pain at } \\
\text { site of } \\
\text { injury }\end{array}$ & $\begin{array}{c}\text { Radicular } \\
\text { pain }\end{array}$ & $\begin{array}{c}\text { Wound } \\
\text { infec- } \\
\text { tion }\end{array}$ & $\begin{array}{c}\text { Symptoms } \\
\text { necessitating } \\
\text { plate/wire } \\
\text { removal }\end{array}$ & $\begin{array}{c}\text { Sympto- } \\
\text { matic } \\
\text { instability }\end{array}$ \\
\hline Surgical & 22 & 9 & 3 & 1 & 1 & 2 & 2 & 0 \\
Conservative & 176 & 23 & 10 & 6 & 4 & 0 & 0 & 3 \\
\hline
\end{tabular}

Complications related to spinal management are shown in Table IV. Clinical assessment was the primary mechanism used to detect these. All patients in this series were incorporated into a follow up programme involving full clinical and urological evaluation at least once every 2 years. In addition, all patients and their family doctors were encouraged to use the 'open door' policy of the centre to resolve all medical or other problems. General complications were not evaluated in this study. Functional outcome was assessed using the Frankel classification. Grades D and E of this classification have functional movement. In the case of operated patients, preoperative status was deduced from the assessments of the referring hospital. These were often inadequate, especially in those cases where the patient had been injured abroad.

Seven of the 96 cervical patients had spinal operations in the acute stage following injury. One of the 4 of these who were initially complete developed functional movement. Thirty two conservatively managed cervical patients were initially complete. Four of these developed functional movement.

Fifteen of the 102 thoracolumbar patients had spinal operations in the acute stage following injury. Four of the 11 of these who were initially complete developed functional movement. Fifty one conservatively managed thoracolumbar patients were initially complete. Four of these developed functional movement.

The average time in weeks from injury until discharge home was 29 weeks for those managed conservatively and 31 weeks for those treated surgically.

\section{Discussion}

This study indicates that no valid comparison can be made between those patients of this series managed surgically and those managed conservatively because the cases were dissimilar in some respects and the numbers treated operatively were so few. The favourable functional outcome of several of the operated patients may be apparent rather than real because the preoperative neurological assessment was often inadequate.

The incidence in this series of complications arising in patients treated conservatively is lower than sometimes quoted. This may be due to the pragmatic approach adopted resulting in subclinical complications not being detected. In our view this approach is justified because complications are relevent only if they affect the quality or duration of the patient's life. Another factor which may reduce the apparent incidence of complications is that approximately one third of our patients have defaulted from the follow up programme. Complications were encountered more frequently in patients 
treated surgically but again strict comparison with those treated conservatively is not possible. It should also be noted that many of the surgical procedures used would not be considered appropriate by the majority of surgeons treating spinal injuries.

The average time spent in hospital during first admission for the patients of this series is approximately 29 weeks. This is more than twice the figure for many centres in other countries, particularly in the United States. In part this is related to the early mobilisation techniques employed in these centres, but the greater numbers of remedial and other staff, together with the more rapid achievement of housing alterations are probably of greater importance. The hospital costs generated by the employment of large numbers of staff render the cost of treating each patient in these centres many times greater than in our centre. Whether the readmission costs are less requires separate evaluation in view of the great importance accorded to formal patient education by other centres. The resource restrictions in this country which limit the numbers of staff that can be employed also delay provision of the suitable home environment that is often a prerequisite for discharge. Accordingly, it remains to be seen whether higher staff ratios or policies of early mobilisation will be more economical or effective in achieving early discharge in this country given its socialised medical structure. No clear conclusion can be drawn from the fact that the total time spent in hospital was longer for those treated surgically. Most of the operations performed did not achieve adequate stability and therefore the period of bedrest was usually unchanged.

Failure to achieve perfect anatomical reduction is deprecated in some centres. This is not the view here. Though it is considered that early reduction of major dislocations is mandatory, minor degrees of deformity are accepted provided there is no suspicion of continued neural compromise. As with subclinical complications so also with radiological reduction it is considered that the paramount consideration is whether or not there are clinical consequences for the patient. Imperfect reduction is of no importance to the patient unless it gives rise to impaired function or a clinical complication. Any surgical intervention contemplated to resolve minor residual malpositioning must hold definite potential advantages before it is implemented.

In conclusion, it is not possible to compare the results of this study with those of other reports because of differences in the patients and the methods of investigation. Trials must be prospective, multicentred, statistically significant and, if possible, double blinded and with independent assessments if valid comparison between treatments is to be made (Collins, 1983; Bracken, 1984). Functional outcome is not the only important factor. It may be that patient expectations, state resources and local considerations will determine which philosophy of spinal treatment is most appropriate for different centres in different countries.

\section{Acknowledgement}

The contents of this paper were presented in poster form at the Annual Scientific Meeting of The International Medical Society of Paraplegia, Denver, USA, 1984. 


\section{References}

BedBrook G 1981 The Care and Management of Spinal Cord Injuries. New York, SpringerVerlag.

Bracken mb, Collins WF et al. 1984 Effect of Methylprednisolone in Acute Spinal Cord Injury. fAMA 251:45-52.

Collins WF 1983 A review and update of experimental and clinical studies of spinal cord injury. Paraplegia 21:204-219.

DONOVAN WH, DwYER AP 1984 An Update on the Early Management of Traumatic Paraplegia (Nonoperative and Operative Management). Clinical Orthopaedics and Related Research 189:1221.

Frankel hl, Hancock DO, Hyslop G, Melzak J, Michaelis LS, Ungar GH, Vernon JdS, WALSH JJ 1969 The value of postural reduction in the initial management of closed injuries of the spine with paraplegia and tetraplegia. Paraplegia 7:179-192.

GAINES RW, Humphreys WG 1984 A Plea for Judgement in Management of Thoracolumbar Fractures and Fracture Dislocations: A Reassessment of Surgical Indications. Clinical Orthopaedics and Related Research 189:36-42.

Guttmann L 1973 Spinal Cord Injuries. Comprehensive Management and Research. Blackwell Scientific Publications, Oxford. 